\title{
A un siglo de los hallazgos de Ciempozuelos
}

\author{
amparo Hernando Grande*
}

En el año 1894 se publicaba en el Boletín de la Real Academia de la Historia una serie de enterramientos campaniformes procedentes del término municipal de Ciempozuelos (Riaño, Rada y Delgado y Catalina Garcia). Cien años después, un grupo de investigadores, bajo la coordinación de M. ${ }^{\text {a }}$ Concepción Blasco, conmemoran este importante hallazgo ofreciéndonos esta obra que trata, y lo consigue, de poner al día la situación del Horizonte Campaniforme en la región de Madrid '.

Consta de una introducción, ocho capitulos realizados por especialistas de cada tema, y una seleccionada bibliografía.

En el Capítulo I, «Inventario General de yacimientos» (13-46), C. Blasco y V. Recuero, presentan una lista completa de todos los yacimientos de la región de Madrid, cincuentaiséis en total, en los que se han producido hallazgos campaniformes. Igualmente presentan un mapa de la distribución geográfica de los mismos, en el cual se observa el desigual reparto de los yacimientos, hecho que las autoras atribuyen, por un lado, a la selección intencionada de determinadas zonas por parte de estas primeras comunidades metalúrgicas, pero también a la falta de atención que las investigaciones arqueológicas han mostrado por las distintas regiones madrileñas, así como a la sobreexplotación de algunas zonas que solamente han permitido recoger restos descontextualizados, como es el caso de la cuenca del Manzanares aguas abajo de Madrid.

En el Capítulo II, “Los Asentamientos» (47-73), C. Blasco, J. Baena y V. Recuero exponen la dificultad que presenta determinar la naturaleza y

\footnotetext{
* Prof. Titular de prehistoria. UNED.

1 Blasco, M. C. (Edi.): El horizonte campaniforme de la Región de Madrid en el centenario de Ciempozuelos. Departamento de Prehistoria y Arqueologia, UAM, Madrid, 1994. 277 páginas con abundantes láminas y figuras de materiales y estructuras, mapas, gráficos, cuadros y tablas.
} 
el significado de los hallazgos campaniformes, la mayoría de ellos están totalmente descontextualizados, otros son fruto de prospecciones o recogidas selectivas exclusivamente superficiales, y los menos han sido objeto de excavación en extensión: Cantarranas, Las Carolinas, Los Vascos, El Ventorro... Teniendo en cuenta estos problemas y con las naturales reservas afirman que las tres cuartas partes de los yacimientos que pueden ser clasificados debieron ser lugares de hábitat.

Los hábitats campaniformes de la región de Madrid corresponden exclusivamente a establecimientos al aire libre, a partir de aquí los autores, basándose en su propia experiencia, ya que son escasos los datos sobre los asentamientos en la bibliografía científica, revisan aspectos tan relevantes como el tamaño y la duración de los asentamientos, las características arquitectónicas, las actividades desarrolladas y la distribución de los mismos, así como su relación con el medio geográfico.

En el Capítulo III, «El Mundo Funerario» (75-99), C. Blasco, M. ${ }^{a}$ L. Sánchez y J. Calle, tratan de los yacimientos campaniformes identificados como funerarios, señalan la inferioridad numérica de éstos en relación con los de tipo hábitat, ya que el número total asciende a diez, de los cuales ocho corresponden a enterramientos, posiblemente individuales, en fosa, práctica funeraria campaniforme más común en la región que nos ocupa. Los otros dos restantes, se tratan de la necrópolis de Ciempozuelos, integrada por al menos siete tumbas, y del dolmen de Entretérminos, único monumento megalítico, y posiblemente también, el único caso de enterramiento colectivo en esta zona perteneciente al Horizonte Campaniforme.

Se describe cada uno de estos yacimientos y los diferentes materiales asociados a ellos. Destacamos por su interés la descripción de dos enterramientos inéditos, hallados recientemente en la localidad de Perales del Río (Getafe, Madrid), en la terraza inferior del Manzanares, y que se inscriben perfectamente dentro del mundo funerario campaniforme de enterramientos individuales en fosa. Si bien aportan novedades de gran interés, como las estructuras de las tumbas, que no son fosas planas, sino que se encuentran señaladas por piedras, y aunque no alcanzan a ser túmulos monumentales, si pudieron constituir señalizadores visibles desde un amplio entorno de la terraza fluvial. Los ajuares de estas dos tumbas son bastante modestos, sólo contienen cerámica, en comparación con otros más completos y ricos, lo que puede interpretarse como diferenciación de status, tradiciones distintas entre los grupos, o simplemente a la incapacidad de algunas de aquellas comunidades, por diferentes causas, a la fuente del metal. 
El Capitulo IV, «La Cerámica» (101-136), está dividido en tres partes, en la primera, C. Blasco, M. L. Sánchez y J. Calle, tratan del Estudio Arqueológico de la Cerámica. En la segunda parte M. ${ }^{a}$ A. Millán y J. G. Arribas, lo hacen del Estudio Tecnológico de la misma, y en la tercera y última C. Gutiérrez del Estudio Microscópico.

En cuanto al estudio arqueológico de la cerámica campaniforme (primera parte), los autores realizan un pormenorizado trabajo acerca de sus formas, decoración, "estilos» y cuestión cronológica. Las formas cerámicas campaniformes ornamentadas están bien definidas en tres tipos: cuencos, cazuelas y vasos. En cuanto a la decoración, es evidente que la cerámica decorada sigue siendo todavía el auténtico fósil-guía del horizonte campaniforme, y que son en los ajuares funerarios donde los ejemplares ricamente decorados constituyen un volumen importante, ya que su presencia en yacimientos de habitación es escasísima, siendo, por el contrario abrumadora la presencia de cerámicas lisas.

Respecto a los «estilos", los autores nos dicen, que en el Horizonte Campaniforme de la región de Madrid, están presentes los cuatro estilos cerámicos: marítimo, puntilado geométrico, Ciempozuelos y Silos, aunque de forma desigual, ya que la variedad Silos apenas está representada y, en cambio, es mayoritario el estilo Ciempozuelos. Igualmente señalan, la dificultad que existe, en función de los datos que ofrece el campaniforme madrileño aceptar una secuencia de "estilos campaniformes", ya que en yacimientos de los que se conoce su contexto, no existe secuencia, sino coetaneidad de estilos, por tanto habria que pensar que los tipos ornamentales son más bien "estilos" practicados por diferentes talleres, que adoptan más de uno, aunque no debe descartarse la posibilidad que en un determinado momento de la secuencia campaniforme tenga más éxito uno $u$ otro estilo.

Por último los autores plantean la cuestión cronológica, señalando la falta de dataciones absolutas fiables, se cita la cronología de un yacimiento calcolítico de Loeches considerado precampaniforme que va entre el $5184 \pm 485$ B.P. y $4264 \pm 298$ B.P., pero nada se puede decir del inicio y del final del Horizonte Campaniforme en la zona que nos ocupa.

El estudio tecnológico de la cerámica (2. parte), es el que nos permite conocer el tipo y las características de los materiales utilizados en la elaboración de las cerámicas. Los autores estudian once muestras de cerámica campaniforme, procedentes de los yacimientos funerarios de Perales del Río, a través de un análisis microscópico de lámina delgada $y$ difracción de rayos $X$. Apreciándose en su composición granos de cuarzo y feldespato, incluidos en una matriz arcillosa oscura con alto 
contenido de hierro, oscilando entre el $20 \%$ y el $40 \%$ del total la proporción de desgrasantes.

Creemos interesante destacar dentro de este estudio, el análisis que los autores realizan, cuestionando el origen humano, de la pasta blanca calcárea que aparece frecuentemente rellenando las cerámicas campaniformes con decoraciones incisa, pseudoexcisa o de peine. Es, sobre todo, a partir del análisis de dicha pasta por microscopía electrónica cuado puede observarse como los cristales de calcita que conforman el relleno presentan una morfología idiomorfa bien desarrollada característica de una precipitación natural del carbonato cálcico. Por lo tanto consideran que en el caso de las muestras estudiadas el relleno de la decoración no tiene un origen humano, siendo en realidad una precipitación natural de carbonato cálcico durante el enterramiento de las cerámicas.

Como colofón de este capítulo, C. Gutiérrez hace referencia al estudio microscópico de las cerámicas campaniformes (3. parte). Se trata de un minucioso análisis sobre diez fragmentos de cerámica, procedentes del yacimiento Km 8,900 izquierda de la carretera de San Martín de la Vega (Perales del Río, Getafe), para conocer mejor la técnica empleada para la ornamentación de la misma a través de una lupa binocular. Lo que ha permitido a la autora llegar a una serie de interesantes conclusiones, entre ellas a como el alfarero trabajaba cada pieza sin demasiada planificación previa, ya que son frecuentes los casos de tramos de líneas sobrepasadas o de trazo irregular, aunque a veces las imperfecciones se deben al gran tamaño de los desgrasantes. $Y$ como en algunas ocasiones se emplean distintos tipos de peines o matrices en una misma pieza para conseguir determinados efectos ornamentales, por ello, nos dice la autora, la diversidad de motivos y composición son la causa de que cada pieza se nos ofrezca como un producto singular.

En el Capítulo V, «Metalurgia Campaniforme y de la Edad de Bronce en la Comunidad de Madrid" (137-171), S. Rovira e I. Montero realizan un magnífico trabajo. Empiezan por señalar lo comprometido que resulta abordar el tema de la metalurgia campaniforme, en estos momentos de revisión de datos e interpretaciones para definir «lo campaniforme». Resaltan, entre otras, dos cuestiones a tener en cuenta para el estudio de la tecnología metalúrgica asociada al fenómeno campaniforme, como es, en primer lugar, el marco cronológico en el que se encuadra este fenómeno en el territorio de Madrid, no en tanto en cuanto a sus comienzos, sino en cuanto a su duración, pues si se acepta la asociación de elementos campaniformes con materiales calcolíticos, no resulta tan evidente la relación de contemporaneidad con materiales del Bronce Antiguo, y sobre todo, del Pleno. En segundo lugar, y desde el punto de vista 
tecnológico el enorme interés que tiene averiguar el modo según el cual se generalizaron, se difundieron y transmitieron los elementos campaniformes y si los conocimientos tecnológicos metalúrgicos se difundieron conjuntamente con esos elementos, es decir, aclarar el interrogante de si existió o no una metalurgia específica campaniforme, y en caso afirmativo poder hablar de ella como hablamos de cerámica campaniforme.

Con estas limitaciones, los autores, intentan definir cuáles son las características de la actividad metalúrgica asociable al período de manifestación del Vaso Campaniforme en Madrid. Son veintiuno los yacimientos de donde proceden materiales metálicos, y se identifican: alabardas, espadas, puñales, hachas, puntas, punzones y objetos de oro. Señalándose, en cada caso, su asociación o no a cerámica campaniforme. El trabajo continúa con el análisis metalográfico de las piezas que permite, no sólo, identificar el cobre como primer componente, y el arsénico el segundo en importancia, sino también, conocer la tecnología de taller, que se inicia con la fundición del objeto en un molde bivalvo, seguida de unos tratamientos de forja para rematar la pieza.

Los autores hacen referencia a los recursos de minerales de cobre que ofrece la Comunidad de Madrid, que se centra en las vertientes del Sistema Central y que ocupan la zona norte y oeste de la región. En cuanto a la tecnología metalúrgica, podemos destacar el empleo de vasijas cerámicas comunes como hornos de fundición, son las denominadas vasijashorno, y no parece que hubiera una técnica especial de elaboración de vasijas para esta finalidad metalúrgica concreta, sino que aprovechaban piezas comunes del ajuar doméstico, lo que pondría en evidencia, a su vez, el carácter doméstico de esta primera metalurgia.

Los autores terminan señalándonos que no parece correcto que pueda hablarse de una metalurgia campaniforme definida por sí misma y de aplicación general, sino de metalurgias asociadas al fenómeno campaniforme. En el caso de la provincia de Madrid, la larga etapa de manifestación del Vaso Campaniforme ofrece unos rasgos metalúrgicos de aire calcolíti$\mathrm{co}$, en la línea de lo que comienza a configurarse como un substrato tecnológico común a buena parte del territorio peninsular desde mediados del III milenio hasta finales del primer tercio del II, sin aparente relación con la «adopción» de los elementos campaniformes.

Capítulo VI: «La producción lítica durante fases calcolíticas: análisis del conjunto del yacimiento campaniforme del Campo de Fútbol (Getafe, Madrid)" (173-226), de J. Baena y M. Luque. Este capítulo se completa con el Apéndice I, «Estudio mineralógico de algunos útiles pulimentados procedentes del Cerro Basura de Pinto", de A. Millán y J. G. Arribas. 
En este capítulo J. Baena y $M$. Luque realizan un estudio detallado y, sobre todo, técnico acerca de los conjuntos líticos aparecidos en el yacimiento del Campo de Fútbol, cuya excavación puso de manifiesto la existencia de diferentes estructuras, con un repertorio de materiales bastante similar, una de ellas mostraba unas características que permiten diferenciarla de las otras, cuyos materiales aparecidos quedaron limitados a restos líticos, en concreto, restos de talla. El primer paso de su investigación pasa por la reproducción experimental de los modelos existentes, en este caso en la reproducción de talla por laminación sobre materiales presentes en la zona, el análisis minucioso de los atributos, veintidós atributos para lascas y trece para núcleos, siguiendo un sistema de clasificación establecido y los procesos de reducción, identificándose dos procesos, la talla laminar y la talla de material rodado-patinado.

En el Apéndice I, A. Millán y J. G. Arribas nos ofrecen el análisis realizado sobre algunos fragmentos de útiles pulimentados hallados en el yacimiento de Cerro Basura de Pinto, para conocer la procedencia de la materia prima empleada en su realización, ya que la industria lítica pulimentada requiere un tipo de piedras que no se encuentran en la zona que nos ocupa, al contrario de lo que sucede con los útiles líticos trabajado por percusión, cuya materia prima es abundante en las cercanías de los asentamientos del Bajo Manzanares.

En el Capítulo VII: “Arqueozoología del Calcolítico en Madrid: ensayo crítico de síntesis» (227-247), A. Morales y C. Liesau, nos ofrecen una valoración histórica, metodológica e interpretativa sobre los conjuntos arqueofaunísticos recuperados en yacimientos calcolíticos de la Comunidad Autónoma de Madrid. Unos de los principales problemas que presenta este trabajo es el mal estado de conservación de los materiales óseos, debido a alteraciones de superficie, aridez de la zona y a la larga exposición a la intemperie. Todo ello afecta, no sólo, a la misma calidad del dato, sino también, puede transmitir imágenes falseadas acerca de la abundancia de especies o incluso de la fauna, ya que los huesos pequeños o débiles son los más afectados por el amplio conjunto de acciones destructivas. Pero los autores señalan, como problema fundamental, de cara a realizar un análisis faunístico en el ámbito geográfico y período seleccionado la propia naturaleza del registro. Pues si el número de yacimientos en donde se consigna fauna es limitado, peor es aún el tratamiento que se le ha dado, con ausencia de análisis actualizados, en el caso de excavaciones antiguas, y la que se reduce a una mera lista de especies, en estudios posteriores. En general, los autores denuncian la falta de familiarización con los materiales analizados que se trasluce en algunas publicaciones, lo que obliga a ser tomadas con extrema precaución y aconsejan recurrir a especialistas. 
A continuación citan los yacimientos calcolíticos madrileños con restos de fauna, seleccionando aquellos más adecuados a efectos de realizar ulteriores análisis comparativos, y son: Cueva y Cerro de Juan Barbero, EI Ventorro (conjunto clave del análisis comparativo), El Capricho y Factoría de Euskalduna. En función de los datos obtenidos, los autores llegan a una serie de conclusiones, de las que destacamos la que hace referencia a la fauna que no parece haber sido un elemento frecuente en yacimientos calcolíticos de la provincia de Madrid, en donde parece haber un predominio de fauna doméstica frente a silvestre, siendo los ovicrapinos los que representan el sector mayoritario en cuanto al número de restos, el porcino y el vacuno compiten por el segundo puesto.

En VIII y último capítulo, "Manifestaciones Simbólicas" (249-263), C. Blasco, V. Recuero, C. Jiménez y C. Gutiérrez, señalan, en primer lugar, la escasez de estas manifestaciones simbólicas en el campaniforme de Madrid, y en la Meseta en general, y que está en consonancia con el débil desarrollo del megalítismo en el interior peninsular. Lo que contrasta con el numerosos repertorio de objetos simbólicos de otras zonas periféricas peninsulares, asociados a los abundantes enterramientos megalíticos, aunque en el caso de Madrid, excepcionalmente, las piezas simbólicas han sido halladas en conjuntos domésticos. Son piezas poco elaboradas y por tanto de difícil interpretación, pero pueden relacionarse con los ejemplares menos elaborados de las áreas megalítica peninsulares.

Los autores analizan un conjunto de fragmentos cerámicos, procedentes de yacimientos de la región de Madrid, con representaciones figurativas de claro carácter simbólico, como animales y astros, y de formas radiales como esquematizaciones astrales.

Junto a esta cerámica simbólica, hay otros dos objetos identificados como «ídolos", procedentes de Cerro Basura (Pinto) y de Camino Tiverilla (Valdemoro), respectivamente. El primero de ellos, se trata de una pieza realizada sobre un guijarro de cuarcita rosácea, con escotaduras laterales simétricas realizadas por percusión y pulimento, confiriéndole una morfología de violín (ídolo-violín). El aspecto general del segundo lo emparenta con los "ídolos-placa", tan abundantes en el occidente peninsular, se trata de una piedra de caliza que mediante pulimento se ha obtenido una forma trapezoidal de caras alisadas, en la superficie superior se han realizado una serie de incisiones paralelas que parecen indicar un peinado, y la cara anterior presenta un piqueteado con lo que parece haber querido marcar dos discos, así como una serie de puntos sobre uno de estos círculos.

Por último, se hace referencia a una estela, procedente de la parte baja de la ladera del cerrete de la pista de motocross en Pinto. Se trata de un 
monolito de caliza, trabajado únicamente en su superficie anterior, de aspecto antropomorfizado. Es una pieza que puede enmarcarse dentro del grupo de "estelas" calcolíticas dentro de la tradición del Arte Megalítico, encajándose en el grupo de «estelas antropomorfas». Los autores le atribuyen una cronología de la primera mitad del II milenio y lo hacen en base a su relación con el Horizonte Campaniforme, ya que el hallazgo se produjo en la ladera del cerrete en cuya cumbre aparecieron las cerámicas campaniformes de "estilo Silos" de momentos finales de ese Horizonte.

Como conclusión, los autores apuntan que estas manifestaciones simbólicas guardan cierto parentesco con las de los dos grandes focos del megalitismo peninsular (occidental y meridional), pero evidencian una simplicidad y aparente tosquedad, posiblemente a causa tanto del tipo de soporte utilizado, como de la poca experiencia del artesano que lo realiza, pero también, por el paulatino enrarecimiento y simplificación que estas manifestaciones evidencian en esta etapa final del Calcolítico. El capítulo termina con un Apéndice en el que $\mathrm{C}$. Gutiérrez expone los resultados obtenidos del reconocimiento, a través de una lupa binocular, del ídolo procedente del Cerro Basura, deduciendo que la pieza fue sometida a un trabajo de elaboración intencionado, pero con posterioridad no fue utilizada en una función que haya dejado huellas de uso evidente, por lo que su significado como posible objeto simbólico parece posible.

La obra finaliza con un amplio, completo y selecto repertorio bibliográfico.

Es ésta una obra sólida, acerca de un tema que necesitaba la investigación actual. Una nueva y buena sintesis producto del interés de todos sus autores por la temática,y buen trabajo de investigador. Es una puesta al día sobre el Horizonte Campaniforme en la Región de Madrid, la variedad de temas, dentro del marco geográfico y cronológico propuesto, supone en cada caso un estado de la cuestión por lo novedoso de sus aportaciones y puntos de vista.

Queremos destacar y al mismo tiempo felicitar a la coordinadora y editora de la obra M. ${ }^{a}$ Concepción Blasco, pues ambas labores exigen un gran trabajo, que ella ha llevado hasta el final con éxito, y esperamos que no sea lo único que quede para el futuro.

En resumen, se trata de un interesante libro, al que todo estudioso del tema deberá acudir y disfrutar con su lectura, como ha sucedido en nuestro caso, lo que, al mismo tiempo, justifica la longitud de esta recensión bibliográfica. 